\title{
O JORNAL ESCOLAR O ESTUDANTE ORLEANENSE: NÃO PODEMOS TORNAR AS CRIANÇAS FELIZES, MAS PODEMOS FAZÉ-LAS FELIZES TORNANDO-AS BOAS (SANTA CATARINA, 1949-1973)
}

\author{
Giani Rabelo \\ Universidade do Extremo Sul Catarinense, Brasil.
}

\section{$\cos 80$}

\section{Resumo}

A idéia de pesquisar sobre o jornal $O$ Estudante Orleanense surgiu no momento em que encontramos vários números do impresso no acervo da EEB Costa Carneiro, localizada no município de Orleans/SC, em uma das etapas de implantação do Centro de Memória da Educação do Sul de Santa Catarina. À época (2010), deparamo-nos com 57 exemplares, além de um livro de atas da Associação Jornal Escolar O Estudante Orleanense. Este artigo se propõe a dar visibilidade às práticas e saberes estudantis, mas, principalmente, compreender a contribuição destes instrumentos informais de educação, jornal e associação, à cultura escolar constituída neste educandário entre os anos de 1949 e 1973, no que concerne ao processo civilizador em curso com a instalação do grupo escolar em nível nacional, estadual e local.

Palavras-chave: jornal escolar, cultura escolar, processo civilizador.

\section{SCHOOL NEWSPAPER O ESTUDANTE ORLEANENSE: WE CAN NOT MAKING CHILDREN HAPPY, BUT CAN DO THEM HAPPY BECOMING THE GOOD (SANTA CATARINA,1949-1973)}

\begin{abstract}
The idea of researching the newspaper O Estudante Orleanense emerged when we found several numbers printed in the collection of EEB Costa Carneiro, located in the city of Orleans/SC in one of the stages of implementation of the Centro de Memória da Educação do Sul de Santa Catarina. At the time (2010), found 57 copies, plus a minute book of the Associação Jornal Escolar O Estudante Orleanense. This article proposes to give visibility to student practices and knowledge, but mainly to understand the contribution of these instruments informal education - newspaper and association - the school culture made this educational institution between the years 1949 and 1973, regarding the civilizing process underway with the installation of the primary school at the national, state and local.
\end{abstract}

Keywords: school journal, culture school, civilizing process. 


\title{
PERIÓDICO ESCOLAR O ESTUDANTE ORLEANENSE: NO PODEMOS \\ HACERLOS NIÑOS FELIZ, PERO PUEDEN HACER LOS FELIZ NIÑOS BUENOS (SANTA CATARINA, 1949-1973)
}

\begin{abstract}
Resumen
La idea de investigar el diario O Estudante Orleanense fue cuando nos encontramos con varios números impresos de la colección de la EEB Costa Carneiro, ubicado en la ciudad de Orleans/SC en una de las etapas de la implementación del Centro de Memória da Educação do Sul de Santa Catarina. En el momento (2010), nos encontramos con 57 copias, además de un libro de actas de la Associação Jornal Escolar O Estudante Orleanense. En este artículo se pretende dar visibilidad a las prácticas de los estudiantes y el conocimiento, pero sobre todo para entender la contribución de estos instrumentos de educación informal - diario y asociación - y la cultura de la escuela hizo esta raza entre los años 1949 y 1973, en relación con el proceso de civilización en marcha con la instalación de la escuela primaria a nivel nacional, estatal y local.

Palabras-clave:periódico escuelar, cultura escolar, proceso civilizador.

\section{JOURNAL DE L'ÉCOLE O ESTUDANTE ORLEANENSE: NOUS NE POUVONS FAIRE POUR ENFANTS HEUREUX, MAIS PEUT FAIRE LES HEUREUX DEVENIR LE BON (SANTA CATARINA,1949-1973)}

\section{Résume}

L'idée de rechercher le journal O Estudante Orleanense est venue quand nous avons trouvé plusieurs numéros imprimés de la collection EEB Costa Carneiro, situé dans la ville d'Orléans/SC dans l'une des étapes de la mise en œuvre du Centro de Memória da Educação do Sul de Santa Catarina. A l'époque (2010), nous sommes confrontés à 57 exemplaires, plus un livre des minutes de Associação Jornal Escolar O Estudante Orleanense. Cet article vise à donner une visibilité aux pratiques des étudiants et des connaissances, mais surtout de comprendre la contribution de ces instruments éducation informelle, journal et association, et de la culture scolaire fait cette race entre les années 1949 et 1973, en ce qui concerne le processus de civilisation en cours avec l'installation de l'école primaire à l'échelon national, étatique et local.

Mots-clé: école journal, école de la culture, processus civilisatrice. 


\section{Introdução}

idéia de trabalhar com o jornal O Estudante Orleanense surgiu no momento
em que nos deparamos com vários exemplares deste impresso estudantil no
acervo documental da Escola de Educação Básica Costa Carneiro ${ }^{1}$, localizada no município de Orleans/SC, em uma das etapas de implantação do Centro de Memória da Educação do Sul de Santa Catarina².

À época, 2010, quando recolhíamos um conjunto bastante vasto de documentos da referida escola para posterior digitalização, chamou-nos atenção a quantidade de exemplares preservados do jornal estudantil. No acervo do referido educandário, entre tantos suportes de memórias escolares, havia 57 exemplares do 0 Estudante Orleanense, publicados nos anos de 1951, 1957, 1959, 1960, 1961, 1962, 1963, 1970, 1971, 1972 e 1973. Do mesmo modo, chamou-nos a atenção um livro de atas com registros das reuniões da Associação Jornal Escolar O Estudante Orleanense, referentes aos anos de 1949 a 1972.

Posteriormente, com a aprovação de outro projeto ${ }^{3}$, foi possível tomar os dois documentos, o livro de atas da associação e o impresso estudantil, como objetos de pesquisa, pois muitas foram as indagações suscitadas no manuseio desses materiais.

Nesse sentido, podemos considerá-los como lugares de memória (Nora, 1993). Estes documentos são espécies de guardiões de uma memória coletiva dos sujeitos que fizeram parte da Escola Costa Carneiro entre os anos de 1949 a 1973 e que foi esfacelada pelo processo de ruptura com o passado, vivenciado pelas sociedades industriais modernas.

Pouco se tem investido em estudos sobre as práticas e saberes estudantis, mesmo sabendo-se que se vive um tempo em que este segmento foi eleito como foco de pesquisa. No campo da História da Educação os impressos estudantis, entre outros objetos, têm alcançado certa visibilidade a partir do movimento do alargamento de temas e do uso de novas fontes.

Especificamente sobre a escrita infantil ou juvenil, Mignot (2005), baseada em Antonelli e Becch (1995), afirma que "a escrita infantil não era objeto de análises até o início da década de 1980, indicando que documentos produzidos pela pena infantil eram material pouco dignos de estudo revelando assim o pouco interesse pela cultura não adulta" (p. 39). Ainda comentando a mesma obra, mais especificamente o artigo de Dominique Julia (1995), Mignot (Ibid.) aponta que ele "observou que trabalhar com a escrita infantil e juvenil, numa perspectiva histórica, é extremamente difícil, pois a documentação de períodos mais antigos é rara e, talvez, não haja outro campo da história com uma taxa de conservação de documentos tão baixa quanto esta" (p. 39).

\footnotetext{
${ }^{1}$ Escola pertencente à rede estadual de ensino de Santa Catarina, localizada na Rua Aristiliano Ramos, 205, Orleans - SC.

${ }^{2}$ O Centro de Memória da Educação do Sul de Santa Catarina abarca um acervo documental de 27 escolas da rede estadual de educação de Santa Catarina, localizadas nas microrregiões do extremo Sul de Santa Catarina. O projeto é desenvolvido desde março de 2009 e conta com recursos do CNPq, da Universidade do Extremo Sul Catarinense e do Programa Cátedras Ipea/Capes para o Desenvolvimento. Ver http://200.18.15.10/muesc/muni 07.php.

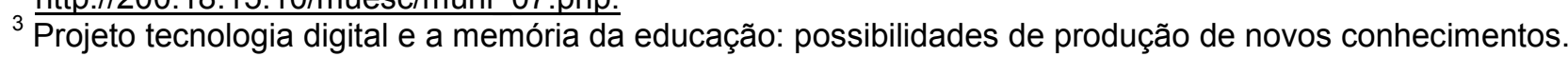


$\mathrm{Na}$ tentativa de atenuar esta lacuna no campo da História da Educação, elegeu-se o jornal $O$ Estudante Orleanense e o livro de atas da respectiva associação como objetos de pesquisa, compreendidos como um instrumento informal de educação que contribuiu para a construção da cultura escolar do Grupo Escolar Costa Carneiro, entre os anos de 1949 a 1973.

Como Viñao Frago (2000), compreendemos que a cultura escolar se configura como um conjunto de ideias, princípios, critérios, normas e práticas sedimentadas ao longo do tempo de existência das instituições educativas uma vez que, no interior delas, são produzidas maneiras de pensar e de agir que propiciam, aos envolvidos nas práticas escolares, desenvolver atitudes, modos de vida, de pensar, hábitos e ritos escolares.

Na produção dos modos de pensar, agir e se comportar, no âmbito do novo modelo de instituição escolar inaugurada na Primeira República, ou seja, o grupo escolar, podemos identificar elementos que anunciavam um intenso e denso processo em direção à modernização do país. Essa intenção está evidenciada no decreto n. 2.991 , de 28 de abril de 1944, encaminhado, pela circular n. 42, de 10 de maio de 1944, aos estabelecimentos de ensino estaduais, municipais e particulares do Estado de Santa Catarina:

O nosso mais acendrado empenho é no sentido de que se procure penetrar o espírito dessa organização, sondando o seu valor como meio disciplinar e como evolução da escola de ontem, quando os princípios sociais não mereciam os cuidados tão necessários à preparação do homem de amanhã. Por intermédio das associações bem orientadas, colocaremos a escola nos moldes compatíveis à evolução, que a vida experimenta, visto ser a fonte preparadora das gerações em caminho de um plano melhor, condizente com a nossa civilização. (Santa Catarina, 1944, p. 1)

Entre tantos aspectos a serem problematizados, chamou-nos a atenção a frase registrada em todos os números do periódico, ano após ano: Não podemos tornar as crianças felizes, mas podemos fazê-las felizes tornando-as boas. Isso suscitou a seguinte questão: que estratégias foram postas em prática para que se desencadeasse um processo civilizador que resultasse em tal intento?

Esta indagação está alicerçada, de forma ainda incipiente, nas reflexões propostas por Nobert Elias (1993) sobre o processo civilizador, entendendo a escola como uma instituição criada pelo Estado Moderno para exercer um controle externo sobre o comportamento das pessoas, a fim de modificá-los, racionalizando atitudes, bem como abrandando pulsões e impulsos e fortalecendo o autocontrole rumo à sociedade civilizada.

O jornal O Estudante Orleanense foi criado no momento em que o estabelecimento emergia como grupo escolar na cidade de Orleans, no extremo Sul de Santa Catarina.

\section{O Grupo Escolar Costa Carneiro e a emergência do jornal 0 Estudante Orleanense}

De acordo com os registros contidos no histórico da EEB Costa Carneiro, a construção do prédio escolar teve início em 1929 na cidade de Orleans, mas foi inaugurado somente em 19 de maio de 1935, com a denominação de Grupo Escolar 
Costa Carneiro. No início, funcionava até o $5^{\circ}$ ano complementar. No ano de 1946 houve a criação do Curso Normal Regional Olímpio Adolfo de Souza Pitanga.

Resultado do presente de casamento do imperador D. Pedro II a sua filha princesa Isabel e ao seu marido Cond'Eu, a colônia ganhou a denominação de Orleans ${ }^{4}$ em 1884 , por ocasião da única visita feita pelo conde. Orleans foi, inicialmente, colonizada por italianos; posteriormente por portugueses, alemães, poloneses e letões.

Nos anos de 1930, a cidade de Orleans encontrava-se em crescimento com economia baseada, principalmente, na agricultura, suinocultura e extração de madeira. Por sua localização, entre a Serra e o Litoral catarinense, constituiu-se em um importante entreposto para o comércio regional.

A escola, que está em funcionamento no mesmo local até os dias de hoje, em um lugar alto e central da cidade, guardou a mesma arquitetura exuberante, chamando a atenção de qualquer visitante.

Figura 1

Grupo Escolar Costa Carneiro, 1950.

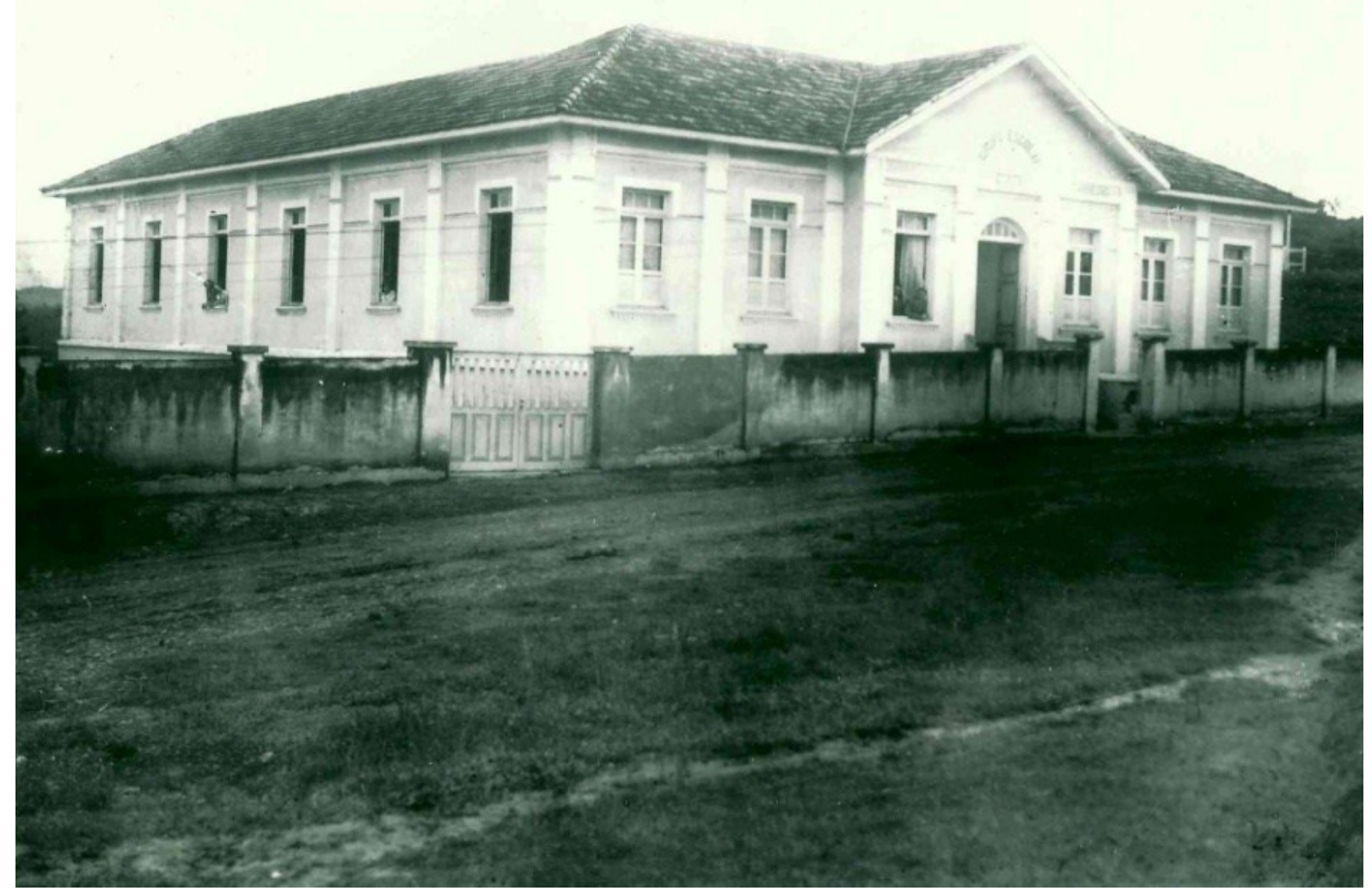

Fonte: Acervo EEB Costa Carneiro

\footnotetext{
${ }^{4}$ A demarcação original do dote de terras abrangia Orleans, parte de São Ludgero, Grão Pará, Rio Fortuna, Santa Rosa de Lima, parte de Anitápolis, Armazém, São Martinho e São Bonifácio.
} 
A arquitetura desse prédio escolar, da forma como se apresentou para a cidade à época, nos leva a pensar sobre um novo modelo de escola primária, implantado pelos republicanos no início do século 20, que fazia parte de um projeto civilizador e modernizador do país:

Estes prédios foram estrategicamente criados em pontos de grande visibilidade social, cravando no imaginário uma idéia de escola que não alcançou um conjunto mais geral da população, mas teve força para seduzi-la. Estas instituições sociais funcionaram como vitrines, mas expunham um produto que não estava à venda; deveria ser reverenciado, admirado, mas estava disponível para poucos. (Silva, 2006, p. 181)

Deste modo, este modelo, que predominou no país durante o processo de urbanização e expansão do ensino público, conviveu com as escolas isoladas existentes na zona rural, responsáveis pela escolarização de um expressivo contingente da população brasileira (Souza, 2004, p. 2).

Entre as normatizações para o funcionamento dos grupos escolares, estabelecidas pela legislação catarinense no ano de 1943, constava a exigência de se criar as associações auxiliares da escola com base nos seguintes argumentos:

O serviço das associações auxiliares da escola tem por fim a reorganização da escola em bases de comunidade social de trabalho em cooperação e sua articulação om o meio social por todas as medidas que tendem a estender seu raio de ação educativa e a tornar estreita a colaboração entre a escola, a família e as outras instituições sociais. Viria, na sua ação educativa: 1-responder aos problemas que surjam às crianças e adolescentes na vida escolar ou doméstica; 2 - incutir o gosto e hábitos de trabalho e de ação, por meio de clubes, concursos, exposições, etc; 3 organizar excursões, teatro, etc. que, satisfazendo aos fins recreativos, possam desempenhar função educativa. Procura oferecer aos alunos oportunidade de exercitar atitudes de sociabilidade, responsabilidade e cooperação, pela organização de associações escolares, estudos em comum, campanhas em prol de aspirações sociais e outras formas de atividade social próprias da infância. (Santa Catarina, 1946, p. 21)

Na circular de n. 32, de 2 de abril deste mesmo ano, expedida pela Secretaria da Justiça, Educação e Saúde, mais precisamente pelo diretor do Departamento de Educação, Elpídio Barbosa, são mencionadas as seguintes associações: biblioteca, liga pró-língua nacional, pelotão de saúde, clube de leitura, círculo de pais e professores, jornal escolar, liga da bondade, orfeão, museu e clube agrícola. Ao todo, dez associações que deveriam ser implantadas gradativamente (Santa Catarina, 1943).

No decreto n. 2.991 , de 1944 , são prescritas as orientações sobre a criação e funcionamento das associações. Cada uma necessitaria manter um livro ata, no qual deveriam ser registrados os conteúdos das reuniões mensais (Santa Catarina, 1944).

No acervo da EEB Costa Carneiro encontramos as atas de várias associações, entre elas: clube agrícola (1937-1945), biblioteca escolar (1945-1972), jornal escolar (19491972), associação desportiva Grajaú Atlético Clube (1954-1965), museu escolar (19551969), clube de leitura (1956-1972), liga pró-língua nacional (1969-1972) e pelotão da saúde (1957-1972). A coexistência de várias associações indica a preocupação, por parte 
da direção escolar, em cumprir as prescrições estabelecidas pela legislação educacional. Além disso, podemos observar que a maioria dos livros de atas se encerra em 1972, levando-nos à seguinte indagação: o que teria ocorrido no ano letivo de 1973 para que o educandário não mais estimulasse a permanência ou criação das associações auxiliares da escola?

Anos depois da publicação do decreto-lei n. 2.991, de 28 de abril de 1944, o Grupo Escolar Costa Carneiro, em 1949, criou a Associação Jornal Escolar, que passou a publicar O Estudante Orleanense.

\title{
As instruções legais para a confecção do jornal escolar
}

As associações auxiliares da escola já eram objeto da legislação estadual desde a década de 1930, seguindo os preceitos nacionais. No entanto, é no decreto-lei n. 2.991, de 1944, que são descritas, de forma bastante detalhada, as normas para o funcionamento das associações.

De acordo com Zen (2006), as associações auxiliares da escola já eram presentes desde o início do século 20 nas escolas brasileiras e catarinenses. Estas

\begin{abstract}
constituiam grupos organizados no interior das instituições escolares primárias, fossem elas públicas ou particulares, com um propósito comum de integrar o corpo discente, estimulando uma formação cívica, moral e intelectual através do exercício de "atitudes de sociabilidade, responsabilidade e cooperação", contribuindo igualmente com o processo de busca por uma identidade nacional. (p. 2335)
\end{abstract}

Sobre o jornal escolar, as normas versam sobre o conteúdo e a forma. Além disso, são apontadas as vantagens de se ter um jornal na escola, bem como orientações sobre o processo de escolha do nome do jornal e da formação da diretoria da associação jornal escolar.

No decorrer de sua existência, o jornal do Grupo Escolar Costa Carneiro sofreu variações em sua denominação. No primeiro ano de circulação denominava-se $O$ Estudante Orleanense, nos anos de 1957 e 1958 recebeu o nome de O Estudante Orleanês, no primeiro número de 1960 passou a se chamar apenas de O Estudante.

Posteriormente, a partir do mês de maio de 1960 até o último exemplar encontrado, novembro de 1973, o nome do jornal voltou a ser O Estudante Orleanense. É bem provável que a denominação do jornal tenha ocorrido após a escolha dos membros da diretoria da associação, com o auxílio do professor orientador, conforme determinação da Secretaria da Justiça, Educação e Saúde/Departamento de Educação:

Num dia e hora previamente designados, os alunos se reúnem na escola, e, a, primeira cousa a se fazer é a escolha do nome do jornal. Para facilitar êsse trabalho, o professor apresentará uma lista de dez nomes em colaboração com as crianças e, dentre esses, será votado um. Para isso, o professor distribue um pedacinho de papel a cada aluno presente e fará a apuração. (Santa Catarina, 1944, p. 10)

Quanto às vantagens de se ter um jornal escolar, primeiramente é apontada a idéia de que o acervo constituído pelos jornais produzidos pelos estudantes poderia servir, 
futuramente, como material de pesquisa para o conhecimento das realizações do passado. Em segundo lugar, defende-se que a alma juvenil é um canteiro e que dela pode brotar, se estimulada, aptidões tão almejadas na formação dos alunos, como narrar, descrever, produzir contos, poesias e crônicas, desenhar e ter uma caligrafia bem desenhada e legível. Em terceiro lugar, o conteúdo do jornal escolar novamente é lançado à condição de material de consulta histórica, mais precisamente sobre a região. Por último, o jornal escolar serviria como um instrumento para que a família pudesse acompanhar o progresso escolar de seus filhos e das demais crianças.

Nas prescrições legais, o corpo do jornal deveria se composto pelo título, localidade, município, data, número, ano e pelos nomes dos dirigentes. Mas o que parecia ser tão simples de se fazer também mereceu um detalhamento por parte da Secretaria da Justiça, Educação e Saúde/Departamento de Saúde. Além de toda a orientação, um modelo do cabeçalho era apresentado a fim de ser seguido.

No mesmo decreto é salientado que o jornal escolar poderia ser: "impresso, mimeografado, dactilografado, manuscrito e falado", no entanto, a recomendação era de que fosse manuscrito em decorrência da "carência de recursos e aparelhagem", considerando que o jornal falado era de "ação muito restrita". Além disso, o jornal manuscrito possibilitaria "a manifestação dos alunos de bôa letra por meio do jornal". (Santa Catarina, 1944, p. 11).

A "bôa letra" (Santa Catarina, 1944, p. 11) já era componente das preocupações das autoridades educacionais desde as primeiras décadas da República. De acordo com Vidal $(1998$, p. 1)

no início do século 20 , em vários estados brasileiros, discursos pedagógicos, apoiados em preceitos higienistas, preocuparam-se em normatizar a escrita. A caligrafia inclinada, utilizada durante o século 19, apesar de "elegante, graciosa e pessoal", era criticada, porque percebida como a causa para os problemas de miopia e escoliose encontrados nos/as escolares.

Investiu-se fortemente para que a caligrafia inclinada fosse substituída pela caligrafia vertical, aconselhada para os escolares. Nesse sentido, era enfatizada "a clareza e a paridade dos elementos constitutivos da letra vertical. A nova escrita, homogênea e impessoal, trazia para o universo escolar a legibilidade e a simplicidade do texto produzido em máquina de escrever" (Ibid., p. 1). Portanto, esta escrita era a mais indicada e necessária às novas exigências postas pela modernidade, ou seja, "o tipo vertical era aquele indicado como o único capaz de preparar o/a aluno/a para o exercício da escrita eficiente necessária ao trabalho no comércio e na indústria" (Ibid, p. 1).

A maior parte dos números do impresso estudantil do Grupo Escolar Costa Carneiro são manuscritos, tendo como suporte a folha pautada ou A4. Poucos foram os números impressos. A maioria dos jornais recebeu algum tipo de ilustração. 
Figura 2

Capa do jornal O Estudante Orleanense, 1951.

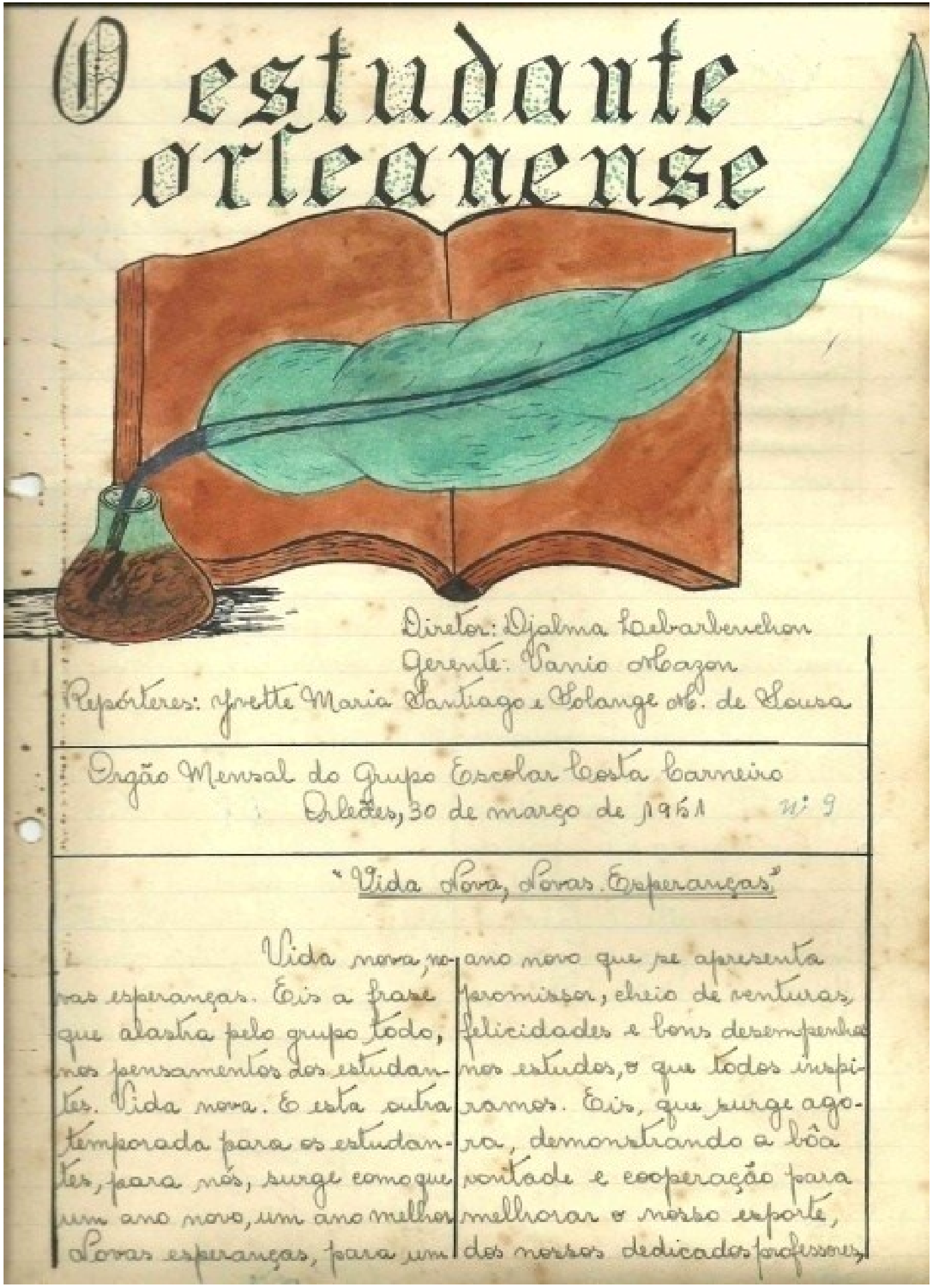

Fonte: Acervo EEB Costa Carneiro 
Figura 3

Capa do Jornal O Estudante Orleanense, 1960.

\section{Estudante Orleanense}

Orbão Mensal dos Alunes do Curso Primário Elementar e Curso Primário Complementar đo Curso Normal Resional "Olímplo Adoifo de Souza Pitanda"

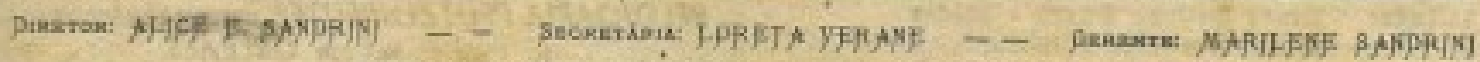

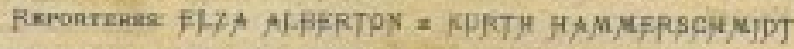

ORLEXES - MES DE NOVEMRRO DE 1960 N

\section{5 ale Novembro}

\section{PROCLAMAÇ̃̃o DA REPÚBLICA}

Os brasileiros sempre desejaram proclamar a Repabilica. D. Pedro era maito bom, mas o povo queria um ßovểrno que fôsse escolhito par eleiçäo.

Por 15so, muitos patriótas ilustres, como Siłva Jardim, Benjamim Constant, Lopes Trovťo, Rai Barbosa, Jallo de Castilhos, Prudente de Morais c outros taziam a propaganda da Repablica

o Exército e a Marinha tambển đesejavam um छovêrno republicano.

Finalmente, na mapha de 15 de novembro de 1689, o marechal Deodoro da Fenseca assumiu o comando das forcas armadns, diriglu-se para a praca đa Aclamaçio, hoje praça República, e cercou o Quartel General, onde se eneontrava reunida o Ministêrio.

Vitoriosa a revoluçăo. cujos chefes foram Deodoro da Fonseca, Flotiano Peixoto e Benjamim Constant, fol constituida no Brasil a Repúbilica.

D. Pedro II e a familia tiveram de sair do pais. A 19 de novembro do mesmo ano, fol criada a Bandeira Nactonal Repablicana. Por tsso, nessa đa. ta, comemora-se o "Dla da Bendeira"

\section{As Férias}

Como sỉo małniflicas as têrias. Para mim ou para qualquer outro ser do mundo $\mathrm{cm}$ que vivemes; funcionários, operários, principalmente parn nós, estudantes; as férias ađ̃o maravilhosas.

Passamos as provas tal qual um presidtírio que espera ancloso os filtimos dias de seu tormento para depois anunciar a sua liberdade por todo o mundo. Assim passamos nós cstudantes. Passamos os meses de aula, as agonlas das provas, porém sempre talando nas férias, que vem ou que já pas. taram, que fizemos durante as férias, se foram boas ou más, onde estivemos, com quem nos encontramos, etc. Enfim, uma infinidade de colsas sobre o assunto aférias:.

A época em que chedam estudantes de todos

\section{DIA DO PROFESSOR}

o dia 15 de outubro é consagrado ao Protessor. Sim, ê o Dia dos Mestres.

$\mathbf{Z}$ é fusto que se đedique a êsses homens e mulheres que dis e noite instraem as mentes em formaç̃o cultivando-Ihes o saber, através do ensium dia especial, uma đata de homenasem.

Mas, vocts periluntarío, por que fot escollhido o dia 13 de outubro? $\mathbf{E}$ porque nesta data, Ia lonbe, no ane de 1827 , fot criada uma lei que obriga. va o ensino primário $\mathrm{em}$ tôdas as cidades e vilas do Brastl.

E quando se fala em tempo antrgo, ligado ì nobre missăo de educar, iembramos que o primeiro mestre ema nossa Pátria fol o Padre José do An. chieta, que ensinou us primeiras letras, a lingus portugatsa, aos nossos indios.

E também precisamos falar em Pestalozzi, famoso mestre itallano que criou modernas normas de educagito infantil nas escolas públicas ou particulares.

Saudemos, portanto, es nessos mestres, honrando saa missĩo espinhosa que deve ser como um sacerdócio.

(Extraido)

cs lados do Brasil, principalmente agut $\mathrm{cm}$ Orleties.

Aos primeiros dias ja começaram as alegrias đas férins: passelos dansas, cinemas, tudo enfim que possamos sozar nestes dias de descanso.

As férias sắo para nós, estudantes orleanenges, como o céu é. para os crentes, e a liberdade para os pissaros ensiaiolados.

Compos de aluna Renite M. Wandscheer - 4 Série C.N.R.

\section{João Ramiro Machado \& Cia.}

Ammarinho, Lougss, Ferragens. Generos alimenticios, ete. Representantes da Farioho de trizo Glórin e Aswear Tijueas Compraes e vendem produtos do lavoura. Beneficiamenta de Arros

O RLE A ES - Rua 15 de Navembro sin - S. C.

Fonte: Acervo da EEB Costa Carneiro 
As poucas edições impressas do jornal O Estudante Orleanense, em torno de seis, correspondentes aos anos de 1960 e 1961, continham propagandas de lojas comerciais locais, talvez como uma das formas de garantir a produção gráfica e custear as despesas.

O nível de detalhamento abrange, inclusive, as formas de organização e apresentação das páginas:

Cada página do jornal deverá ser riscada pelo meio, deixando de cada lado uma margem de um a dois centímetros. Nas primeiras páginas devem ser copiados os artigos para, em seguida, serem lançados outros trabalhos com diferentes títulos que melhor satisfizerem a sua orientação" (Santa Catarina, 1944, p. 11).

As regras postas e exigidas pela legislação catarinense em relação à forma e ao conteúdo do jornal escolar certamente vinham ao encontro dos desígnios do grupo escolar, tornando-se um importante instrumento no processo civilizador que esta instituição necessariamente deveria desencadear junto aos estudantes, seus familiares e sociedade local.

Pode-se inferir, ainda, que o cuidado, o capricho e o esmero a serem dedicados à produção do jornal escolar estão implicados em uma estratégia, no sentido de torná-lo um objeto que pudesse oferecer aos leitores uma determinada leitura acerca do grupo escolar e o quanto era importante tal instituição para a sociedade.

Um jornal bem elaborado e bem apresentado, demonstrando muito daquilo que a escola e seus estudantes poderiam produzir, certamente causaria impacto junto aos familiares e estreitaria os laços entre estes e a direção da escola e seus docentes. Além disso, funcionaria como um instrumento no processo civilizador a ser desencadeado pelo educandário, inculcando hábitos, repassando códigos de moral e de conduta e impondo os valores almejados pelo ideário republicano.

\section{A Associação Jornal Escolar e 0 Estudante Orleanense: os vestígios preservados}

Os números encontrados do jornal O Estudante Orleanense, no acervo da EEB Costa Carneiro, correspondem aos anos de 1951, 1957 a 1958, 1960 a 1963 e 1970 a 1973, portanto, existem algumas lacunas. Ao todo foram preservadas 57 edições.

Além dos jornais foi encontrado, junto ao acervo, um livro de atas no qual há registros das reuniões da Associação Jornal Escolar O Estudante Orleanense, referentes aos anos de 1949 a 1973, com exceção dos anos de 1952, 1953 e 1954. O referido livro tem como suporte um caderno pequeno, brochura, com capa dura, encapado com papel pardo. Após a conclusão das atas, estas eram encaminhadas à direção da escola.

Localizar um conjunto de jornais e atas da associação significa poder adentrar no cotidiano da escola por uma passagem não oficial, que aos poucos revela jeitos distintos de aprender, ensinar, escrever e desenhar de certa época. Cabe acrescentar que estes documentos podem ser utilizados como porta de entrada para melhor compreender a produção das pedagogias instauradas no grupo escolar, pois servem como espécie de observatórios privilegiados do conteúdo ensinado e registrado, que privilegia uma história das práticas, regras e culturas escolares. Portanto, estes documentos trazem vestígios 
das práticas escolares, dos ritos, dos saberes que constituíram a história educacional da EEB Costa Carneiro.

$\mathrm{Na}$ tabela 1, apresentamos o número de reuniões realizadas mensalmente, bem como os números do jornal encontrados.

Tabela1

Reuniões da Associação do Jornal Escolar O Estudante Orleanense e os números do jornal escolar (1949 a 1973).

\begin{tabular}{|c|c|c|}
\hline Anos & Número de reuniões & Número de exemplares \\
\hline 1949 & 5 & - \\
\hline 1950 & 9 & 1 \\
\hline 1951 & 3 & - \\
\hline 1955 & 3 & - \\
\hline 1956 & 3 & 1 \\
\hline 1957 & 3 & 2 \\
\hline 1958 & 3 & - \\
\hline 1959 & 6 & 6 \\
\hline 1960 & 3 & 7 \\
\hline 1961 & 3 & 2 \\
\hline 1962 & 3 & - \\
\hline 1963 & 3 & - \\
\hline 1964 & 3 & - \\
\hline 1965 & 3 & - \\
\hline 1966 & 3 & - \\
\hline 1967 & 3 & - \\
\hline 1968 & 3 & 8 \\
\hline 1969 & 3 & 9 \\
\hline 1970 & 3 & 8 \\
\hline 1971 & 3 & 7 \\
\hline 1972 & 2 & 57 \\
\hline 1973 & & \\
\hline Total & 73 & - \\
\hline
\end{tabular}

Fonte: Acervo da EEB Costa Carneiro.

Ao que parece, as reuniões foram mais freqüentes no início, ou seja, nos anos de 1949 e 1950. Este último foi o ano com maior número de reuniões, nove ao todo, ocorridas nos meses de março a novembro, sem interrupção. Posteriormente, o número de reuniões diminuiu, bem como passaram a acontecer, de forma mais regular, nos meses de março, junho e novembro. Ao todo foram 73 reuniões, considerando que nos anos letivos de 1952 a 1954 não há registros.

Analisando os exemplares, podemos inferir que foi no ano de 1971 que houve maior número de jornais produzidos: nove números que abrangem quase todos os meses do ano letivo. Depois, estão os anos de 1963 e 1972, ambos com oito jornais mensais. Não foi identificado nenhum número produzido nos meses de janeiro, fevereiro e dezembro, em função do período reservado às férias escolares. Ao todo, foram 57 exemplares localizados no acervo da EEB Costa Carneiro. No entanto, não foi encontrado nenhum exemplar dos anos de 1949, 1950, 1952, 1953, 1954, 1955, 1956, 1964, 1965, 1966, 1967, 1968 e 1969. 
Ao compararmos a freqüência das reuniões com os números de jornais encontrados, surgem as seguintes indagações: os números não localizados foram realmente produzidos? Se produzidos, por que alguns foram conservados e outros descartados? E se não foram produzidos, quais os motivos?

Sobre a tiragem do jornal, a Secretaria da Justiça, Educação e Saúde/ Departamento de Educação também instituiu orientações a serem seguidas:

Cada número do jornal escolar deve ser, pelo menos, reproduzido três vezes. Um, destina-se ao arquivo do Departamento de Educação, que só organiza a ficha à vista do jornal e não da comunicação de ter sido o mesmo fundado. A reprodução do jornal deverá ser feita assim que o diretor faça a distribuição do material, ficando cada um dos demais membros da direção incumbido de auxiliar nessa reprodução. No estabelecimento deve ficar um número para o arquivo. Caso haja conveniência os números destinados ao estabelecimento poderiam ser copiados diretamente num só livro, cujo tamanho fôsse igual ao do jornal. Os números, a mais, destinam-se à leitura dos alunos e, aos assinantes, se houver.(Santa Catarina, 1944, p. 10-11).

Esta determinação evidencia que havia, por parte do órgão estadual, a preocupação em preservar este documento no arquivo escolar. Se esta regra foi obedecida ou não é algo difícil de avaliar, dada a limitação deste estudo. No entanto, é possível afirmar que nesta escola houve uma preocupação importante com a preservação dos documentos, caso contrário não seriam encontrados estes números após mais de sessenta anos de fundação da Associação Jornal Escolar O Estudante Orleanense.

Esta atitude por parte dos dirigentes escolares atende, em certa medida, aos novos interesses emergentes no campo da História da Educação. A partir do final da década de 1980 muitas investigações têm buscado "invadir a caixa-preta da escola com o intuito de compreender seu funcionamento interno, a constituição do currículo e as práticas diárias de professores e professoras, alunos e alunas" (Vidal, 2004, p. 3). Estes registros auxiliaram, sobremaneira, na compreensão do processo de criação e produção do jornal estudantil em questão.

\section{Os registros das reuniões da Associação Jornal Escolar e O Estudante Orleanense: organização e produção}

Os registros encontrados no livro de atas oferecem pistas as quais permitem supor que O Estudante Orleanense eram produzido desde 1949, quando a escola ainda se denominava Grupo Escolar Costa Carneiro, ou seja, 14 anos após sua inauguração. Inúmeras reuniões foram realizadas para a organização do periódico, o que indica a existência de outros números do jornal, além dos 57 encontrados. Na primeira reunião, ocorrida no dia 18 de abril de 1949, o principal assunto foi a reorganização da diretoria, o que pressupõe que a Associação do Jornal Escolar já existia. Talvez tenha existido outro livro de atas que não foi preservado pela escola.

Quanto à circulação do jornal antes de 1951, ano em que encontramos um único número, pode-se conjeturar que o jornal estudantil já circulava, uma vez que nas atas das reuniões ocorridas entre os anos de 1949 e 1950 há menção da necessidade de escolha de bons artigos para o jornal. Na ata da reunião de abril de 1950, "o Diretor falou na 
obrigação e necessidade de que os membros se esforçassem para a escolha de artigos para o jornal" (Associação Jornal Escolar, 1950, 11) ${ }^{5}$.

Ao recorrermos à ata da primeira reunião ocorrida no ano de 1955, no dia 19 de março, encontramos o seguinte enunciado: "Ata de Reunião de reorganização jornal $O$ Estudante Orleanense, do Grupo Escolar Costa Carneiro, de Orleães, no ano de 1955" (Associação Jornal Escolar, 1955) ${ }^{6}$.

Esta anotação, diferente daquelas que eram realizadas a cada primeira reunião do ano letivo, ao invés de aparecer no corpo da ata, está no cabeçalho, como se fosse uma chamada. Este pormenor leva à dedução de que tenha ocorrido uma retomada dos trabalhos paralisados por algum tempo. Talvez isso explique a ausência de registros do funcionamento da associação nos anos de 1952, 1953 e 1954 e, conseqüentemente, a não localização de jornais neste período.

É provável que a ausência dos números dos jornais referentes aos anos de 1951 a 1957, 1957 a 1959 e 1963 a 1970, exceto os de 1952, 1953 e 1954, em que a associação parece não ter funcionado, indique a cultura do descarte, uma vez que é algo muito comum em escolas.

No final do ano de 1966 aparece o Relatório do Jornal O Estudante Orleanense e nele consta a seguinte citação: "Cumprindo as determinações da Secretaria de Educação e Cultura ${ }^{7}$, apresento o relatório das atividades do ano de 1966" (Relatório da Associação Jornal Escolar, 1966, p. 71$)^{8}$. Nele são relatadas, de forma sintetizada, as atividades desenvolvidas.

As reuniões da Associação Jornal Escolar aconteciam no próprio estabelecimento, em salas distintas, denotando não existir uma sede própria. Nas atas constam nomes das salas como: Carlos Gomes, Duque de Caxias, Machado de Assis e Tiradentes. O local mais utilizado pela associação foi a sala Carlos Gomes.

A prática de nomear as salas homenageando os vultos da história do Brasil assinala a preocupação em instigar, naqueles que nelas circulavam, a devoção aos heróis brasileiros e o sentimento de patriotismo. Intrigante é o fato de que essas salas com estas denominações atravessaram diferentes décadas permeadas por distintos projetos políticos nacionais.

Como a escola foi inaugurada em 1935, talvez essa tenha sido uma prática implantada a partir do Estado Novo que servia para a formação dos valores cívico-morais dos estudantes, além de desempenhar um papel fundamental na afirmação e manutenção do regime político do Estado Novo. É notório que estes ambientes escolares foram organizados dessa forma com o intuito de fortalecer os valores patrióticos.

A Associação do Jornal O Estudante Orleanense existiu por mais de 20 anos, exigindo dos alunos e alunas da escola um apreciável nível de organização. Várias equipes foram estruturadas e reestruturadas a fim de compor a diretoria da Associação Jornal Escolar, responsável pela sua confecção do jornal.

\footnotetext{
${ }^{5}$ Reunião realizada em 25 de abril de 1950

${ }^{6}$ Reunião realizada em 19 de março de 1955

${ }^{7}$ Nova denominação da Secretaria da Justiça, Educação e Saúde.

${ }^{8}$ Relatório de 15 de dezembro de 1966.
} 


\section{A composição da diretoria da Associação Jornal Escolar O Estudante Orleanense e o papel da professora orientadora}

Cada associação que era implantada na escola primária deveria ter uma diretoria. $\mathrm{Na}$ diretoria da Associação Jornal Escolar havia os seguintes cargos: diretor, gerente, secretário e repórteres. O cargo de secretário não aparece nas determinações oficiais do Departamento de Educação de Santa Catarina.

Todavia, alertava-se que a votação deveria "recair em quatro dos alunos mais capazes da escola" (Santa Catarina, 1944, p. 10). Se a principal exigência para compor a diretoria era ser um mais capaz, é possível pressupor que a escolha dos membros não ocorria abertamente. Certamente havia uma pré-seleção que envolvia estudantes com desempenho escolar elevado. Ser um dirigente da Associação Jornal Escolar significava ser um exemplo para os demais.

O número de repórteres poderia sofrer uma variação nos grupos escolares, "tendose em vista o número de classe e a perfeição do trabalho que lhes compete. Os repórteres acrescidos serão auxiliares, e escolhidos por designação, por isso, não aparecem no cabeçalho do jornal" (decreto-lei n. 2991, de 28 de abril de 1944, p. 10).

Em todas as reuniões da associação esteve presente a figura da professora orientadora, que costumava fazer uso da palavra. Essa professora era escolhida pela direção da escola e tinha o atribuição de orientar as crianças para que elas mesmas fossem capazes de gerir a associação. Nas palavras de Zen (2006, p. 2335), "o objetivo do associativismo escolar era, entre tantos outros, estimular e permitir que o corpo discente fosse responsável pela gestão de cada associação, sendo o professor responsável apenas o coordenador".

Os nomes destas professoras, em geral, não são mencionados nas atas das reuniões da Associação Jornal Escolar O Estudante Orleanense. Um detalhe importante é que, mesmo estando presentes nos encontros, elas não assinavam as atas. No corpo dos registros são encontrados apenas os nomes das professoras orientadoras Olinda Fortes Hannerschmidt (1950) e Manarim Stopassoli (1960).

Importante assinalar que em 1959, na ata da primeira reunião do ano, ao invés de uma professora orientadora, como de costume, aparecem duas professoras orientadoras: Serjinia Carmem Zanini Pinter e Lacy E. Mariot Cordini. Cabia à professora orientadora coordenar as reuniões. Em algumas ocasiões a direção da escola também participava das reuniões.

Mesmo havendo toda uma expectativa em relação ao papel do professor orientador nas associações em geral, esta função parece não ter sido algo fácil e isenta de críticas. Na circular n. 76, de 16 de agosto de 1943, consta a seguinte advertência dos docentes:

O Departamento de Educação tem conhecimento de que professores se queixam de excesso de trabalho, em virtude das associações auxiliares da escola. Dizem os professores que elas Ihes trazem tal soma de serviços, esgotando as suas forças e invadindo até as suas horas de lazer; que a sobrecarga de serviço os deixa terrivelmente desanimados, sacrificados, etc. Isso surpreendeu ao Departamento de Educação, pelo absurdo dessas reclamações. Verificou o Departamento o seguinte: 1) que as associações auxiliares da escola vêm, na sua mor parte, sendo dirigidas e executadas, em tudo e por tudo, pelo professor; 2) que a colaboração dos 
alunos tem sido nula; 3) que o professor executa todo o serviço, aparecendo somente o aluno, "in nomine"; 4) que há jornal escolar feito exclusivamente pelo professor (redação, etc, e até a feitura (escrever do jornal); 5) que os recortes para os alunos são feitos pelo professor; 6) que o colar os recortes nos álbuns também é feito pelo professor, e assim por diante. Tudo é feito pelo professor e o aluno assina, como se fosse seu trabalho. (Santa Catarina, 1945, p. 71)

A repreensão é intensificada ainda mais na circular $n .76$ :

O professor quer apresentar trabalho perfeito para impressionar. Daí, açambarcar todo o serviço da associação auxiliar da escola: o professor faz o que dez, quinze ou vinte alunos deveriam fazer. E deseja dizer que o trabalho foi executado por eles. Isso é doloroso e funesto: ensina, pelo exemplo, a mentira na sua mais plena acepção. Desejamos o trabalho da criança: com os seus mal traçados primeiros passos (maus recortes, álbum, às vezes, lambuzado de goma, artigos e notícias feitos com a graça de quem está engatinhando, etc), e, através deles, no tempo e no espaço, poderemos observar a sua evolução. Não pode haver professor sacrificado, em virtude das associações auxiliares da escola. O professor é orientador, supervisionador, e a criança é a executora. Não se deve desvirtuar o sentido elevado das associações da escola. (Santa Catarina, 1945, p. 72)

Mas o Departamento de Educação não apenas repreendia, mas também orientava o trabalho do professor responsável. No caso do jornal escolar sugere-se: "3) que o jornal pode ficar deficientemente redigido; 4) que, ao passar as notícias e artigos para o jornal, o aluno pode copiar mal, má letra e mau desenho, e além da diversidade de letra"(Santa Catarina, 1945, p. 72).

Pela análise das atas e dos cabeçalhos dos jornais, vê-se que a diretoria tinha o mandato de um ano e a cada início do período letivo era realizada uma nova eleição. Esse procedimento só não foi identificado no ano de 1970, ocasião em que a diretoria mudou na metade do ano. $\mathrm{Na}$ ata não foram encontradas manifestações que justificassem tal decisão.

Ao lançarmos um olhar na perspectiva do gênero, podemos perceber a seguinte composição, conforme o gráfico que segue. 
Gráfico 1

Composição da diretoria da Associação Jornal Escolar O Estudante Orleanense (1949-1973).

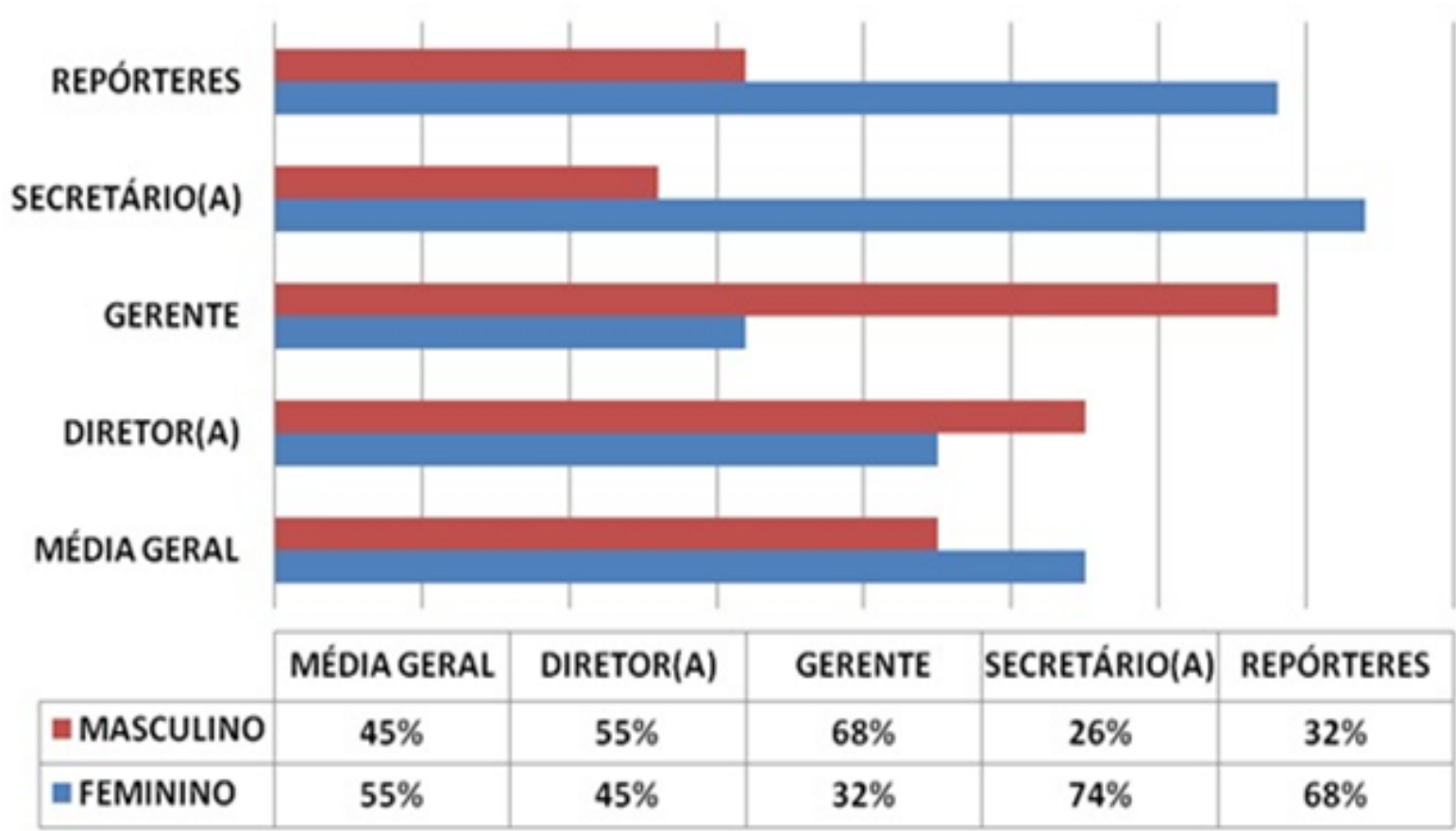

\section{REFERENTE AOS ANOS DE 1949 A 1973}

Nota: Não foram computados os cargos referentes à1968 e 1969, pois nestes anos constam nas atas três diferentes funções: presidente, secretário e suplentes.

Fonte: Livro Ata Associação Jornal Escolar (1949-1972) e jornal O Estudante Orleanense (19511973) da EEB Costa Carneiro.

A partir dos dados do gráfico 1, pode-se afirmar que houve maior participação das alunas na diretoria da Associação Jornal Escolar $O$ Estudante Orleanense durante os mais de 20 anos de sua existência. No quadro geral, a participação feminina foi de $55 \%$ e a masculina de $45 \%$. Esta participação quase equilibrada também ocorreu no cargo de diretor, com o maior índice ficando para o segmento masculino (55\%), e menor para o feminino (45\%). A função de gerente foi mais ocupada por meninos $(68 \%)$, a função de secretário e repórter, mais por meninas.

Mesmo sendo a maior parte dos cargos ocupada por alunas, percebe-se que as funções hierarquicamente superiores foram ocupadas mais por alunos, no caso dos cargos de diretor e gerente. Já os cargos executivos foram ocupados mais pelas alunas, ou seja, secretário e repórteres.

Esta evidência nos faz pensar sobre o que Lustosa (2009) aponta sobre a construção histórica dos papéis sociais atribuídos aos homens e às mulheres, promovendo uma desigualdade justificada, muitas vezes, pela inferiorização do gênero feminino. Um hipotético determinismo biológico atribuído à mulher fundamenta uma 
condição de submissão excluindo-as da vida pública, levando-as a ocupar funções consideradas menos importantes.

Buscar artigos para o jornal era uma obrigação de todos os membros da diretoria, mas em especial dos repórteres. No entanto, o trabalho em equipe era algo cobrado veemente nas reuniões para que o jornal mantivesse regularmente sua tiragem e a qualidade dos artigos.

\section{Trabalhando em equipe: a coleta dos artigos, a qualidade e regularidade do jornal}

A qualidade dos artigos foi algo debatido, com freqüência, nas reuniões. A professora orientadora solicitava, constantemente, que fossem mais variados, interessantes e instrutivos. Mas é provável que alguns artigos tenham sofrido algum tipo de censura por parte da professora orientadora, pois as normativas previam este tipo de procedimento: "Qualquer trabalho destinado ao jornal, embora necessite sofrer a censura do professor, nem por isso deve perder o cunho de originalidade sem o que iriamos destoar os fins desse trabalho de cooperação, que é o jornal” (Santa Catarina, 1944, p. 11).

A prerrogativa, anunciada amiúde, de que "os artigos selecionados, com moral elevada e de alto valor intelectual, fazem do jornal uma leitura aconselhável para todos os alunos do educandário" (Associação Jornal Escolar, 1950) ${ }^{9}$, denota uma forte preocupação com a formação, não só intelectual, mas também moral. Neste sentido, os membros da diretoria eram intimados a se esmerar na escolha dos artigos:

O Diretor falou na obrigação e necessidade de que os membros se esforçassem para a escolha de artigos para o jornal. Todos prometeram tudo fazer para que $O$ Estudante Orleanensefosse um veículo de novos conhecimentos para os alunos do educandário. (Associação Jornal Escolar, 1951, p. 21)

A necessidade da regularidade do periódico compunha a maior parte dos registros, sendo o motivo para inúmeras repreensões verbais, levando a inferir que, apesar da organização da associação e o acompanhamento da professora orientadora, nem tudo funcionava conforme as deliberações. Anotações como: "Falou a Senhora Professora Orientadora, que uma vez reconhecido o fato do atraso, esperava que isto não mais se repetisse" (Associação Jornal Escolar, 1950, p. 16)111; "A professora orientadora pediu mais uma vez os alunos encarregados da execução deste órgão, fazer o jornal antes do dia 30 de cada mês, pois o mesmo fica sempre atrasado" (Associação Jornal Escolar, 1959 , p. 44) ${ }^{12}$, denunciam os atrasos na produção do jornal O Estudante Orleanense.

É recorrente, nas atas, a ressalva sobre a importância do trabalho cooperativo por parte da equipe, com a finalidade de garantir a qualidade dos artigos, bem como a boa apresentação e regularidade do jornal. Este apelo era costumeiramente feito pela

\footnotetext{
${ }^{9}$ Reunião realizada no dia 25 de maio de 1950.

${ }^{10}$ Reunião realizada no dia 25 de abril de 1951.

${ }_{11}^{11}$ Reunião realizada no dia 30 de setembro de 1950.

12 Reunião realizada no dia 20 de agosto de 1959.
} 
professora orientadora ou pela direção da associação. O excerto que segue anuncia esta preocupação:

O assunto da reunião versou sob a boa cooperação dos alunos para que este órgão continue sempre em grande atividade [...]. A professora orientadora convidou a diretoria a trabalhar com ânimo e vontade na boa e natural apresentação do jornalzinho. (Associação Jornal Escolar, 1949, p. $4)^{13}$

Neste sentido, comunicados eram realizados com tom de advertências à equipe, talvez com o intento de torná-la mais cumpridora de seus deveres como responsável pela Associação Jornal Escolar e, conseqüentemente, pela produção do jornal O Estudante Orleanense. Expressões como: "mais pontualidade e perfeição", "bem honrar o nome que figura o alto deste nosso humilde órgão escolar", "trabalhar com mais estima", "zelar cada qual pelo cargo, que, Ihe fora indicado", "trabalhar com ânimo e boa vontade para melhor apresentação do jornal", "trabalhar com mais zelo na execução da sua tarefa" são evidências dessas cobranças que persistiram durante todo o período de existência da entidade produtora do periódico.

Em resposta, nos registros das atas, os membros da diretoria parecem prontificar-se a colaborar mais, pois: "unanimemente prometeram tudo fazer no semestre, com mais perfeição e pontualidade para melhor honrar o nome que figuram no alto deste nosso humilde órgão escolar" (Associação Jornal Escolar, 1958) ${ }^{14}$.

Apesar das advertências, a professora orientadora tecia agradecimentos pelo comprometimento da diretoria:

Agradeceu a todos por terem cooperado com tão boa vontade e carinho para a tiragem, durante o ano do referido órgão escolar; Palavras sinceras de agradecimento, foram dirigidas a diretoria desta associação que muito se esforçou pelo engrandecimento do "Jornal Escolar"; Não poupando esforços para o progresso do "Jornal Escolar" quer na parte da distribuição mensal, quer na parte intelectual, quer na parte referente ao modelo do mesmo e ainda o esmerado cuidado para com a coluna social e humorística (Associação Jornal Escolar, 1961) ${ }^{15}$.

Fazer parte da diretoria da associação significava não poder se desligar desse compromisso, inclusive durante as férias escolares. Em várias reuniões a professora orientadora desejava que todos fizessem boas provas e tivessem boas férias, mas recomendava "como passatempo uma boa leitura" e que reiniciassem o ano ou o segundo período "com muita disposição e boa vontade para estudar e organizar o nosso jornalzinho" (Associação Jornal Escolar, 1956, p. 30) ${ }^{16}$.

O comportamento dos diversos integrantes que assumiram cargos na diretoria da Associação Jornal Escolar O Estudante Orleanense foi alvo de muita vigilância, controle e preocupação. Uma vez que o jornal escolar era um forte instrumento no processo civilizador a ser desencadeado pelo Grupo Escolar Costa Carneiro, estava, então, nas

\footnotetext{
${ }^{13}$ Reunião realizada no dia 18 de abril de 1949.

${ }_{14}^{14}$ Reunião realizada em abril de 1949.

15 Reunião realizada em 25 de maio de 1950.

${ }^{16}$ Reunião realizada em 14 de novembro de 1956.
} 
mãos dos integrantes da diretoria alcançar esse propósito. Para isso, era preciso que seus comportamentos fossem exemplares diante dos demais estudantes e dessem testemunhos de uma dedicação infatigável para a associação. Afinal, o jornal O Estudante Orleanense só conseguiria imprimir novos códigos de conduta nos alunos caso seus dirigentes fossem exemplo, ou seja, cultos, inteligentes, responsáveis, organizados e obedientes, ou seja, civilizados.

\section{Considerações finais}

O grande número de exemplares do jornal O Estudante Orleanense encontrados no acervo da EEB Costa Carneiro denota a preocupação que o educandário teve em preservar seus documentos.

Fazer parte da diretoria da Associação Jornal Escolar O Estudante Orleanense parece ter sido uma tarefa árdua, uma vez que, além da responsabilidade em conseguir os artigos, coletar informações e organizá-las, seus membros deveriam levar esta responsabilidade para os períodos de férias ou recessos escolares.

A qualidade dos artigos do jornal era cobrada firmemente, mas, apesar disso, os artigos nem sempre alcançavam a moral elevada e o alto valor intelectual desejado pela professora orientadora. Neste caso, ela estava autorizada, pelo Departamento de Educação, a censurar o conteúdo dos textos.

A periodicidade também foi exigida insistentemente, mas, pelas lacunas encontradas em relação aos números, pode-se afirmar que a regularidade mensal nem sempre foi obedecida. Estas cobranças eram acompanhadas de advertências, denotando um clima tenso nas reuniões. Para tentar regularizar sua publicação, estratégias foram pensadas e colocadas em prática para que os alunos e alunas produzissem seus artigos.

A instalação do Grupo Escolar Costa Carneiro na cidade de Orleans e a criação das oito associações em seu interior, bem como a permanência destas por mais de 20 anos, foi algo estrategicamente pensado. Resultado das políticas educacionais que foram implementadas gradativamente no país, a partir do início do século 20, o grupo escolar e as associações auxiliares da escola contribuíram, sobremaneira, para a naturalização de novos hábitos, costumes e boas maneiras que nada tinham de natural, mas que foram ditados pela elite republicana na tentativa de serem incorporados pelos sujeitos escolares, em especial as crianças. A naturalização de uma nova cultura escolar, pautada na idéia de que não podemos tornar as crianças felizes, mas podemos fazê-las felizes tornando-as boas, foi perseguida à custa de muitas cobranças, a fim de torná-las mais obedientes e cumpridoras de seus deveres.

O processo civilizador protagonizado pelo Departamento de Educação do Estado de Santa Catarina cravou suas bases de sustentação em uma legislação meticulosa que atingia o cotidiano escolar.

As determinações cunhadas pelo decreto-lei n. 2.991 parecem ter funcionado como uma espécie de manual de instrução para as diretorias das associações de jornais escolares, não só para a sua elaboração, mas também para moldar comportamentos dos estudantes e professores, dentro e fora da sala de aula.

No caso da Associação Jornal Escolar O Estudante Orleanense, as estratégias para atingir o corpo discente e docente partiram não só das várias circulares, regulamentos e 
decretos, mas também da dinâmica implantada na própria associação, na relação dos membros da diretoria com as professoras orientadoras e a direção escolar.

O jornal O Estudante Orleanense e o seu processo de produção nos levam a pensar sobre os artifícios de naturalização de uma cultura escolar permeada por práticas e saberes que não estavam dados, mas que foram construídos sistematicamente por um conjunto de regras.

Princípios, idéias, normas e práticas foram sedimentadas ao longo do tempo de existência da Associação Escolar do Jornal Escolar O Estudante Orleanense. Atingiram, primeiramente e de forma mais direta, os membros da direção da associação e, posteriormente, os leitores, nos quais se procurava produzir maneiras de pensar e de agir adequadas às premissas anunciadas na legislação relacionada ao jornal escolar. Sob a tutela da professora orientadora, serviu como elemento forte na construção da cultura escolar do Grupo Escolar Costa Carneiro.

\section{Referências}

ANTONELLI, Quinto; BECCHI, Egle (a cura di). Scritture bambine: testi infantili tra passato e presente. Roma: Laterza, 1995.

ASSOCIAÇÃO AUXILIAR JORNAL ESCOLAR "O ESTUDANTE ORLEANENSE". Grupo Escolar Costa Carneiro. Ata da reunião realizada no dia 10 de abril de 1949.

ASSOCIAÇÃO AUXILIAR JORNAL ESCOLAR "O ESTUDANTE ORLEANENSE". Grupo Escolar Costa Carneiro. Ata da reunião realizada no dia Reunião realizada em 25 de abril de 1950.

ASSOCIAÇÃO AUXILIAR JORNAL ESCOLAR "O ESTUDANTE ORLEANENSE". Grupo Escolar Costa Carneiro. Ata da reunião realizada no dia 25 de maio de 1950.

ASSOCIAÇÃO AUXILIAR JORNAL ESCOLAR "O ESTUDANTE ORLEANENSE". Grupo Escolar Costa Carneiro. Ata da reunião realizada no dia 10 de julho de 1950.

ASSOCIAÇÃO AUXILIAR JORNAL ESCOLAR "O ESTUDANTE ORLEANENSE". Grupo Escolar Costa Carneiro. Ata da reunião realizada no dia 30 de agosto de 1950.

ASSOCIAÇÃO AUXILIAR JORNAL ESCOLAR "O ESTUDANTE ORLEANENSE". Grupo Escolar Costa Carneiro. Ata da reunião realizada no dia 30 de setembro de 1950.

ASSOCIAÇÃO AUXILIAR JORNAL ESCOLAR "O ESTUDANTE ORLEANENSE". Grupo Escolar Costa Carneiro. Ata da reunião realizada no dia 25 de abril de 1951.

ASSOCIAÇÃO AUXILIAR JORNAL ESCOLAR "O ESTUDANTE ORLEANENSE". Grupo Escolar Costa Carneiro. Ata da reunião realizada no dia 19 de março de 1955.

ASSOCIAÇÃO AUXILIAR JORNAL ESCOLAR "O ESTUDANTE ORLEANENSE". Grupo Escolar Costa Carneiro. Ata da reunião realizada no dia 10 de junho de 1956.

ASSOCIAÇÃO AUXILIAR JORNAL ESCOLAR "O ESTUDANTE ORLEANENSE". Grupo Escolar Costa Carneiro. Ata da reunião realizada no dia 14 de novembro de 1956.

ASSOCIAÇÃO AUXILIAR JORNAL ESCOLAR "O ESTUDANTE ORLEANENSE". Grupo Escolar Costa Carneiro. Ata da reunião realizada no dia 10 de novembro de 1958.

ASSOCIAÇÃO AUXILIAR JORNAL ESCOLAR "O ESTUDANTE ORLEANENSE". Grupo Escolar Costa Carneiro. Ata da reunião realizada no dia 20 de agosto de 1959. 
ASSOCIAÇÃO AUXILIAR JORNAL ESCOLAR "O ESTUDANTE ORLEANENSE". Grupo Escolar Costa Carneiro. Ata da reunião realizada no dia 3 de junho de 1960.

ASSOCIAÇÃO AUXILIAR JORNAL ESCOLAR "O ESTUDANTE ORLEANENSE”. Grupo Escolar Costa Carneiro. Ata da reunião realizada no dia 15 de dezembro de 1966.

ELIAS, Norbert. O processo civilizador. Rio de Janeiro: Jorge Zahar, 1993.

GASPAR da SILVA, Vera Lucia. Vitrines da República: Os Grupos Escolares em Santa Catarina (1889-1930). CONGRESSO LUSO-BRASILEIRO DE HISTÓRIA DA EDUCAÇÃO, 6, 2006, Uberlândia, Anais ... Uberlândia: SBHE/UFU, 2006.

HISTÓRICO. EEB Costa Carneiro, s.n.

JULIA, Dominique. Documenti della scrittura infantile in Francia. In: ANTONELLI, Quinto e BECCHI, Egle (a cura di). Scritture bambine: testi infantili tra passato e presente. Roma: Laterza, 1995, p. 5-24.

MIGNOT, Ana Chrystina Venancio. Vitrine de guardados: exposições de escritas ordinárias como estratégia de preservação da memória escolar. Resgate, São Paulo, n. 14, 2005. Disponível em <http://www.cmu.unicamp.br/seer/index.php/resgate/article/ view/195/196>. Acesso em: 8 ago., 2001.

NORA, Pierre. Entre a memória e a história: a problemática dos lugares. In: Projeto História. São Paulo, n.10, 1993, p. 7-28.

NUNES, Clarice. História da educação brasileira: novas abordagens de velhos objetos. In: Teoria e Educação. Porto Alegre, n. 6, 1992, p. 151-182.

SANTA CATARINA, Circular n. 32, Florianópolis, 2 de abril de 1943. Acervo do Arquivo Público do Estado de Santa Catarina.

SANTA CATARINA. Decreto n. 2.991, 28 de abril de 1944. Acervo do Arquivo Público do Estado de Santa Catarina.

SANTA CATARINA. Decreto n. 3735, de 17 de dezembro de 1946. Acervo do Arquivo Público do Estado de Santa Catarina.

SAVIANI, Dermeval. O legado educacional do longo século XX brasileiro. In: SAVIANI, Dermeval; ALMEIDA, Jane de; VALDEMARIN, Vera Teresa; SOUZA, Rosa de. O legado educacional do século XX no Brasil. Campinas: Autores Associados, 2006, p. 9-57.

SOUZA, R. F. Lições da escola primária: um estudo sobre a cultura escolar paulista ao longo do século 20. CONGRESSO BRASILEIRO DE HISTÓRIA DA EDUCAÇÃO, 3, 2004, Curitiba, Anais Curitiba: SBHE, 2004.

VIÑAO FRAGO, Antônio. El espacio y el tiempo escolares como objeto histórico. Contemporaneidade e Educação. Rio de Janeiro: Instituto de Estudos da Cultura e Educação Continuada, n. 7, 2000, p. 93-110.

VIDAL, Diana Gonçalves. Da caligrafia à escrita: experiências escolanovistas com caligrafia muscular nos anos 30. Rev. Fac. Educ., São Paulo, v. 24, n. 1, 1998. Disponível em <http://www.scielo.br/scielo.php?script=sci arttext\&pid=S0102-25551998000100009\& lng=pt\&nrm=iso >. Acesso em: 5 ago., 2012.

VIDAL, Diana Gonçalves. Apresentação. In: O acervo escolar: organização e cuidados básicos. São Paulo: Centro de Memória da Educação, 2004.

ZEN, Mariane Werner. Brasileiros pelas letras: atividades de associações auxiliares da escola no grupo escolar Alberto Torres (1941-1959) - Brusque/Santa Catarina. 
CONGRESSO LUSO-BRASILEIRO DE HISTÓRIA DA EDUCAÇÃO, 6, 2006, Uberlândia, Anais ... Uberlândia: SBHE, 2006.

GIANI RABELO tem mestrado em Educação pela Universidade Federal de Santa Catarina e doutorado em Educação pela Universidade Federal do Rio Grande do Sul. É professora na Universidade do Extremo Sul Catarinense desde 1996 e atua no curso de Pedagogia e no Programa de Pós-Graduação em Educação.

Endereço: Rua Severino Pizzetti, 150 - 88815-094 - Criciúma - SC - Brasil.

E-mail: gra@unesc.net.

Recebido em 14 de agosto de 2012.

Aceito em 28 de março de 2012. 